\title{
Disaster Preparedness in the Kingdom of Saudi Arabia: Exploring and Evaluating the Policy, Legislative Organisational Arrangements Particularly During the Hajj Period
}

\author{
Abdullah Alyami ${ }^{1}$, Camille Lillian Dulong ${ }^{1,2,3 *}$, Mustafa Z. Younis ${ }^{4}$, Sara Mansoor ${ }^{5}$
}

\author{
${ }^{1}$ Subsea 7, Al Khobar City, SAUDI ARABIA \\ ${ }^{2}$ Canadian Agency for Drugs and Technologies in Health, CANADA \\ ${ }^{3}$ University of Newcastle, NSW, AUSTRALIA \\ ${ }^{4}$ Jackson State University, Jackson, MS, USA \\ ${ }^{5}$ The University of Sydney School of Pharmacy, NSW, AUSTRALIA \\ *Corresponding Author: camille_dulong@hotmail.com
}

Citation: Alyami, A., Dulong, C. L., Younis, M. Z. and Mansoor, S. (2021). Disaster Preparedness in the Kingdom of Saudi Arabia: Exploring and Evaluating the Policy, Legislative Organisational Arrangements Particularly During the Hajj Period. European Journal of Environment and Public Health, 5(1), em0053. https://doi.org/10.29333/ejeph/8424

\section{ARTICLE INFO}

Received: 24 Jan. 2020

Accepted: 26 Feb. 2020

\section{ABSTRACT}

This paper examines the natural disasters that have historically taken place in the Kingdom of Saudi Arabia, particularly during Hajj (the largest mass gathering event in the world). A literature search of multiple databases was conducted to identify what is currently known about the effectiveness of disaster management arrangements, policies and plans in the KSA.

Keywords: disaster, preparedness, Saudi Arabia, floods, mass gatherings, Hajj, accidents

\section{INTRODUCTION}

The Centre for Research on the Epidemiology of Disasters (CRED) in Brussels, Belgium, defines a disaster as a "situation or event, which overwhelms local capacity, necessitating a request to national or international level for external assistance; an unforeseen and often sudden event that causes great damage, destruction and human suffering” (World Health Organization, 2009). The World Health Organization (WHO) (2009) states one of the following criteria must be met to record a disaster into the worldwide database:

- Ten or more people reported killed

- 100 or more people reported affected

- Declaration of a state of emergency

- Call for international assistance

The natural disasters are categorised into meteorological, geophysical, hydrological, climatological and biological causes (Table 1) (World Health Organization, 2009). In 2017, the worldwide disaster database, EM-DAT, recorded 335 natural disasters worldwide, affecting over 95.6 million people, claiming 9,697 human lives and costing approximately US $\$ 335$ billion worth of material damage (Centre for Research and Epidemiology Disasters (CRED), 2017).
Recently, international agencies have significantly increased their focus on disaster management with four areas of focus including promoting humanitarian values, disaster response, disaster preparedness, and health and communitycare (Lindell et al. 2006). In December 1999, a global strategic initiative was developed after the UN General Assembly's vote to establish the International Strategy for Disaster Reduction (ISDR) (United Nation, Office for Outer Space Affairs (UN SPIDER)). This was reinforced by the Hyogo and more recently Sendai Framework for Disaster Risk Reduction (Aitsi-Selmi et al., 2015).

Due to globalization and the volatility of global economy, the negative effects and impact of natural and manmade disasters extend beyond the borders of one country (Coppola, 2006, 2007). Moreover, Saudi Arabia is no exception when dealing with natural and manmade disasters and is a unique case. The country is considered the economic powerhouse of the Middle East by being one of the world's largest exporter of fossil energy and the site of the largest religious pilgrimage (1.2 billion Muslims) (OEC, 2017). Further research is necessary to explore the disaster policies currently implemented in the Kingdom of Saudi Arabia (KSA). This paper details the most recent (in 2015) disasters occurring at Hajj, resulting in 2000 deaths and many others injured.

The KSA government does not disclose the research or the relevant data that has been conducted on disaster 
Table 1. Disaster sub-group definition and classification by CRED

\begin{tabular}{|c|c|c|}
\hline $\begin{array}{l}\text { Disaster } \\
\text { Subgroup }\end{array}$ & Definition & Disaster Main Type \\
\hline Geophysical & Events originating from solid earth & $\begin{array}{l}\text { Earthquake, Volcano, Mass } \\
\text { Movement (dry) }\end{array}$ \\
\hline Meteorological & $\begin{array}{l}\text { Events caused by short-lived/small to meso scale } \\
\text { atmospheric processes (in the spectrum from } \\
\text { minutes to days) }\end{array}$ & Storm \\
\hline Hydrological & $\begin{array}{l}\text { Events caused by deviations in the normal water } \\
\text { cycle and/or overflow of bodies of water caused } \\
\text { by wind set-up }\end{array}$ & Flood, Mass Movement (wet) \\
\hline Climatological & $\begin{array}{l}\text { Events caused by long-lived/meso to macro scale } \\
\text { processes (in the spectrum from intra-seasonal to } \\
\text { multi-decadal climate variability) }\end{array}$ & $\begin{array}{l}\text { Extreme Temperature, } \\
\text { Drought, Wildfire }\end{array}$ \\
\hline Biological & $\begin{array}{l}\text { Disaster caused by the exposure of living } \\
\text { organisms to germs and toxic substances }\end{array}$ & $\begin{array}{l}\text { Epidemic, Insect Infestation, } \\
\text { Animal Stampede }\end{array}$ \\
\hline
\end{tabular}

Source: (Organization, 2009)

management. This is a significant barrier for further research and development of disaster management in the country as it is unknown whether current management strategies have been successful or not.

There is a lack of ongoing investigations and initiatives taking place and the ability to identify the key causes of a disaster along with poor public awareness and communication to civilians regarding potential disasters. Although some government sources claim there is ongoing development and future planning for disaster relief and support, there is no indication of these policies or outcomes.

Although the KSA is geologically stable and is located in southwest Asia by the Arabian Peninsula, there are a variety of severe weather conditions, such as floods, heatwaves and droughts. Moreover, the frequency of natural disasters in the KSA can be partly due to the diverse geography, ranging from mountainous or valley regions to coastal regions and to the extreme dry deserts (Alamri et al., 2011). Earthquakes and volcanic activity in north-western regions, floods in the southwest mountainous regions and flood hazards in the central and western regions are also areas of concern for the country and may cause significant disruption (Alshehri et al., 2016). Additionally, central and eastern regions encounter shifting sand dunes and dust storms. These natural hazards have caused 14 disasters between in 1980 and 2010, taking 484 lives and costing over US $\$ 1$ billion (Alshehri et al., 2016).

Natural and manmade disasters extend beyond the borders of a country or geographical location, having repercussions that are felt globally through economies (Coppola, 2006, 2007). The KSA, is no exception when it comes to dealing with natural and manmade disasters. It is considered the economic power of the Middle East region being largest exporter of the fossil energy in the world and the site of religious pilgrimage for 1.2 billion Muslims (OEC, 2017).

In contrast, manmade routine emergencies have a significant impact in KSA. According to the Ministry of Interior in Saudi Arabia, a leading cause of mortality in the country is motor vehicle accidents (MVAs) and continues to be on the rise. In 2008, vehicle accidents caused 6,000 deaths in the country, almost 12 times higher than all the lives lost from natural disasters over the past 30 years. Moreover, the country has the highest incidence of accidents (including pedestrians) compared to all other Gulf countries (Mansuri et al., 2015).

Globally, there is a desire to develop strategies to reduce the damage of disasters on populations by significantly increasing the disaster management (Bronfman et al., 2019). However, the capabilities of organisations and governments, varies according to political, technological, economic and other factors (Coppola, 2007). The initial steps of global strategic development proceeded after the UN General Assembly's vote in December 1999 and established the International Strategy for Disaster Reduction (ISDR) (United Nation, Office for Outer Space Affairs (UN SPIDER)). This global initiative was accompanied by the Hyogo Framework and more recently the Sendai Framework for Disaster Risk Reduction (Aitsi-Selmi et al., 2015).

Disaster management is a critical element of modern society that requires constant attention and evaluation. The aim of this paper is to identify what is currently known about the risks (i.e., hazard and the characteristics that make people and places vulnerable) the KSA is facing as well as the disaster management strategies for mass gatherings, motor vehicle crashes (MVCs), floods and recommendations for improved response time or measures for these disasters. This review pays particular attention to epidemic outbreak, floods and the major stampede events at the Hajj, the most recent of which occurred in 2015 and resulted in 2000 deaths and many injuries (Alqahtani et al., 2017).

\section{BACKGROUND AND CONTEXT}

The KSA is located in the west of the Asian continent taking up a large portion of the Arabian Peninsula. The frequency of natural disasters in the country is due to the diverse geography, ranging from mountainous and valley 
Table 2. Disasters in the KSA Since 2000

\begin{tabular}{|c|c|c|c|}
\hline $\begin{array}{l}\text { International Disaster } \\
\text { Database Record of } \\
\text { Disaster Type }\end{array}$ & Year & $\begin{array}{l}\text { Number of } \\
\text { Deaths }\end{array}$ & Event Description \\
\hline Epidemic outbreak & 2000 & 57 people & $\begin{array}{l}\text { Meningitides W135 outbreak was reported earlier } 1992 \text { in KSA. However, the epidemic } \\
\text { outbreak re-occurred again at Hajj in 2000, which infected many residents and pilgrims. } \\
\text { This number is excluding the death of people who were infected after the pilgrims } \\
\text { returned their homes and possibly carried the virus back. }\end{array}$ \\
\hline Rift Valley fever outbreak & 2000 & 87 people & $\begin{array}{l}\text { Outbreak started in the south of KSA where residents started reporting large numbers of } \\
\text { cattle, sheep and goats becoming sick and dying. Soon after this, the residents from the } \\
\text { same region were reported with high numbers of haemorrhagic fever by local medical } \\
\text { services to the Ministry of health, which the authorities declared a pandemic outbreak } \\
\text { (Rift Valley pandemic). }\end{array}$ \\
\hline Floods & 2002 & $\begin{array}{l}41 \\
\text { people }\end{array}$ & $\begin{array}{l}\text { Makkah was flooded due to heavy rain for two days, reaching a water level of six metres, } \\
\text { leading to devastating consequences to Makkah residents. }\end{array}$ \\
\hline Terrorist attack & 2003 & 43 people & $\begin{array}{l}\text { Foreign workers housing compounds in Riyadh were attacked by a group of terrorists, } \\
\text { whose vehicles were packed with a large number of bombs. This attack was deemed a } \\
\text { critical incident which the armed forces had to respond to and surrender the whole } \\
\text { region. }\end{array}$ \\
\hline Flood & 2004 & 13 people & $\begin{array}{l}\text { Heavy rains fell in the southern region of KSA, flooding Jizan city, causing many } \\
\text { fatalities and more than } 400 \text { residents homeless. }\end{array}$ \\
\hline Flood & 2005 & 29 people & $\begin{array}{l}\text { More heavy rains fell in the city of Medina, in western of KSA. The flood was so } \\
\text { destructive, that it damaged the Yatamah dam killing many people and destroying over } \\
90 \text { homes. }\end{array}$ \\
\hline Flood & 2009 & 163 people & $\begin{array}{l}\text { Recorded as the worst flood in the history of KSA. A rainstorm started in the early } \\
\text { morning of November } 29,2009 \text {, with strong winds in Jeddah region and flooding the city } \\
\text { in several hours. Hundreds were evacuated and thousands of properties were destroyed. } \\
\text { The estimated cost of the flood's destruction exceeded US } \$ 90 \text { million. (See Appendix 2) }\end{array}$ \\
\hline Hajj stampede & 2015 & 2000 people & $\begin{array}{l}\text { On } 24 \text { September 2015, a large number of pilgrims died due to 'crush and stampede' } \\
\text { incident occurred in Makkah during performing a religious ritual in Mena. }\end{array}$ \\
\hline
\end{tabular}

International Disaster Database, WHO 2010 \& Alamri, 2014

regions to coastal regions and dry deserts (Alamri, 2010). Other contributing factors to Saudi Arabia's disaster list are human related issues such as MVCs, human stampedes and infectious disease outbreaks. These factors are particularly a concern and more prevalent at Hajj.

Additionally, the KSA does not have an official public database to record disasters that have taken place. Most data originate from daily newspapers or other forms of publications that recorded or reported on disasters in the country. As a result, this paper utilizes and references the International Disaster Database (IDD) from the WHO. Recorded information in the IDD has been compared with data distributed in relevant literature and newspapers around the time of the events, to ensure accuracy of the provided information (nternational Disaster Database (EM-DAT), 2010).

Table 2 lists the KSA's worst disasters in the past 20 years, demonstrating the consistent themes of floods, human stampedes and disease epidemics.

\section{Natural Disasters: Flood}

Floods can be life-threatening depending on the size of flood and where they occur. In the KSA, floods are more common on the west side of the country (Abosuliman et al., 2013). For instance, Jeddah, largest city in the Makkah province located by the Red Sea, is home to approximately four million people (Appendix 1). This city usually has a low flood risk due to its dry climate and small amount of rain in the winter. However, in 2009, the city experienced an unfavourable 90 millimetres of rain in under four hours, causing the worst flash flood in country's history (Abosuliman et al., 2013). Despite the government's immediate response to the flood involving police, ambulance and firefighter services to rescue flood victims, the flood took 163 lives and damaged 8,000 properties (Alamri, 2010, 2011).

Studies have conducted on the 2009 Jeddah flood by the Saudi government and other organizations to improve disaster management strategies. For example, Geographic Information System (GIS) and satellite images, as well as terrain change detection studies, have been done to identify the main cause of the flood (Alqahtani et al., 2017). Although natural disasters are unpredictable, the investigation and research on the 2009 flood suggested there was a poor emergency response due to a lack of knowledge and previous experience in flood disaster management, resulting in a large number of casualties (Abosuliman et al., 2013).

\section{Human Related Disasters: Motor Vehicle Accidents}

Human related disasters are just as common as natural disasters and can have detrimental effects on populations. For instance, car accidents are considerably common and can have serious effects on residents, the environment and economic development. Moreover, car accidents are one of the leading causes of disasters in the KSA (Saudi Gazette, 2016; Mansuri et al., 2015). In 2010, approximately $20 \%$ of the hospital beds in KSA were occupied by victims of road accidents while $81 \%$ of hospital deaths were caused by road traffic incidents (Mansuri et al., 2015). Many deaths caused by MVCs or collisions are due to non-compliance of road safety laws, high-speed driving and unmaintained roads. Motor vehicle accidents often involve multiple victims, causing higher rates of mortality and morbidity rates in KSA (Ministry of Interior, 2016). According 
to a report by the Saudi Arabian Red Crescent and Traffic Department, over 526,000 MVCs occur annually and cause 17 deaths every day (Saudi Gazette, 2016).

According to the WHO, road traffic casualties are common in all countries but more so in developing countries (World Health Organization, 2013). Road accidents are a leading cause of death in the KSA and account for $4.7 \%$ of all deaths (Mansuri et al., 2015). However, in developed countries such as the United Kingdom (UK), Australia or United States (US), road traffic fatalities do not exceed $1.7 \%$ of all deaths (Mansuri et al., 2015). Moreover, road accident deaths in the KSA has increased over the last ten years from 17.4 to 24 per 100,000 population (Mansuri et al., 2015). However, road traffic mortalities only claimed five per 100,000 population per annum in the UK, and ten per 100,000 population per annum in the US (Mansuri et al., 2015). Road traffic casualties is considered a major public safety concern in developed countries, like the US and UK, while developing countries do not prioritize road traffic safety or do not have the resources to implement proper measures to reduce road traffic (Mansuri et al., 2015).

In developing countries such as the KSA, the high rate of road accidents is directly related to the social and economic development of the country. The cities of Riyadh, Jeddah, Makkah, Madinah, and Qassim have the highest rate of road accidents compared to other regions in the country as a result of more cars and road congestion in these cities (Mansuri et al., 2015). However, there is little known about the correlation between road accidents and seasons or holidays. Moreover, road accidents are highest during the holy month of Ramadan (fasting month) and may be due to impaired level of consciousness when fasting in extreme summer temperatures leading severe dehydration and lack of concentration (Alamri, 2010; Khammash and Al-Shouha, 2006). An observational study conducted at the Al-Noor Hospital in Makkah, concluded that emergency admissions were highest during the time of Ramadan and were directly related to the fasting in extreme temperature conditions (Alamri, 2010).

Consequently, the gross national income loss caused by road accidents, in the KSA, is between $2.2 \%$ and $9 \%$ while the G8 countries (France, Germany, Italy, the United Kingdom, Japan, the United States, Canada, and Russia) have a gross national income loss between 1\% to 2\% (Mansuri et al., 2015).

\section{Human Related Disasters: Mass Gathering and the Hajj Pilgrimage}

Every year around two million Muslims congregate to Makkah during the month of Ramadan month. This annual pilgrimage is part of the belief that good deeds become greater when they fast and pray around the Kabba (Alamri, 2010). Due to the large crowd numbers and the warm climate conditions, people experience high physical demand to perform their daily prayers and other religious rituals, which can lead to severe consequences. This as a result can cause a major strain on the health care system as well as exhausting available resources in Makkah (Alamri, 2010).

Hajj is one of the oldest and largest regular mass gatherings in the world. Each year approximately three million people gather over the course of five days in one mosque with a total area of $400,000 \mathrm{~m}^{2}$, increasing the likelihood of a human stampede or epidemic taking place (Shujaa and Alhamid, 2015).

In the past decade, the KSA disaster management system has paid particular attention to disaster prevention and management at Hajj due to an increased risk of disasters during mass gatherings (Abosuliman et al., 2013). The gathering of large crowds is of considerable interest to epidemiologists due to the high probability risk of spreading infectious diseases and can impact the local health care system (Soomaroo and Murray, 2012). Consequently, the large number of pilgrims, poor sanitation and hygiene practices during mass gatherings can contribute to the risk of infectious diseases and epidemics. This puts extensive pressure on the Ministry of Health and the surrounding health facilities, in order to prevent and control infectious diseases during Hajj. On the other hand, health care facilities and hospitals have improved to better respond to infectious and non-infectious Hajj-related emergencies (Al-Shareef et al., 2017; Alzahrani et al., 2012). Although there have been significant improvements towards Hajj risk mitigation and disaster planning, disasters still occur even in recent years (Alamri, 2010). For instance, the 2015 stampede disaster due to failure in crowd control led to 2,000 deaths. However, the government has yet to release any information on the reason for the lack of crowd control and future preventative plans.

\section{Government Policies and Support}

In the KSA, none of the government websites outline the country's national disaster plan for disaster management and relief. However, there is a national arrangement proposed by Ministry of Interior (MOI) with the cooperation from various resources and services, in which every organisation creates their own disaster plan (Alrazeeni, 2015). For instance, the Saudi Red Crescent Authority (SRCA) and Ministry of Health have collaborated to develop a health plan which is then submitted to the MOI, who is then responsible for examining all plans and allocating responsibilities to relevant departments or offices (Alrazeeni, 2015). The objective of this arrangement is for organisations to work together at local and regional levels in various parts of the KSA as each of these organisations have different specialities and resources to improve and oversee disaster response. However, there is concern that these regional and local organizations are not receiving enough attention in terms of the implementing these policies and framework (Alrazeeni, 2015).

\section{KSA Government Disaster Management Act}

Disaster management arrangements in the KSA began over 80 years ago and have been continuously improving ever since. The KSA government created a specialised organisation specifically for Hajj, named the Ministry of Hajj and Omrua. This department is responsible for collaborating with emergency services and the Ministry of Health to prevent and reduce disaster risks posed to the public during Hajj (Abubakar et al., 2012).

Disaster management for Hajj was initiated more than 80 years ago in the KSA with main objective of establishing a fire detachment in Makkah in 1927 and was overseen by the Makkah Commonplace Council (Alamri, 2010). In 1948, the Makkah Fire Brigade joined the later-settled Centre of General 
Security to frame the General Security and Fire Services (Alamri, 2010).

Over the next 32 years, the General Security and Fire Services developed five fire units in Makkah alone and five in Medina, Jeddah, Riyadh, Qasim and Dammam to improve disaster management and response (Alamri, 2010). In 1965, a Royal Decree by King Faisal broke up the General Security and Fire Services, as suggested by the international Association of Firefighters, and established the General Directorate of Civil Defence (GDCD) (Alamri, 2010).

The scope of the GDCD was more extensive than the General Security and Fire Services as it applied to all nonmilitary personnel protection in times of peace and in times of wars. Additionally, the organization began working in other urban and rural areas in the Kingdom supported by the advances in media transmission systems (Alamri, 2010).

In 1987, King Fahad proposed a change to the GDCD's structure, objectives, and obligations as recommended by the International Association of Fire Fighters. GDCD conducted research on neighbouring nations and other countries to explore common barriers and issues regarding disaster response and management. Moreover, the Civil Defence Law ensures effective regulation and operations required to protect residents, public and private properties from the risks of disaster events. Furthermore, it guides the response and rescue of those affected by such disasters, ensuring safe transportation and securing national resources at times of peace and disasters. After broad consultation, the current Civil Defence Law announced, that 36 areas will be listed under the department (Alamri, 2010).

The legislation identified the key roles of the GDCD for disasters and conflicts:

- Arranging the national alert system, in the case of disasters or assaults by an armed force, including terrorists.

- Controlling key infrastructure including buildings, electrical lines, roads and arranging evacuations and shelters plans.

- Protection of victims and giving essential life-support measures in affected areas.

- Controlling hazardous areas and directing residents away from dangers.

- Collaboration with other organisational bodies (e.g. police, firefighters and Department of Transportation) to ensure safe evacuation.

- Monitoring the recovery process and restoring day-today usual businesses.

\section{Structure of the General Directorate of Civil Defence (GDCD)}

Currently the GDCD is structured into three key elements: the Board of GDCD, the Executive Committee, and volunteers (Alamri, 2010). The following outlines the roles of each component.

\section{Board of GDCD}

The Minister of Interior is chairman of the board and the Assistant Minister of Interior is the deputy-chairman. A number of sectors and divisions of the GDCD work with the board including fire and police services and emergency medical services. Members are usually appointed by a Royal Decree after approval by chairman or deputy chairman (Alamri, 2010). The Board of GDCD is responsible for the following:

1. Building up general GDCD legislations and arrange future plans and agendas.

2. Building up security and wellness principles that must be met in all undertakings to guarantee non-military personnel well-being and ensure open and private properties.

3. Setting up rules for preparing programs for GDCD workforce.

4. Setting up arrangements for the enlistment of GDCD volunteers and characterizing their parts and rights.

5. Shaping divisions of the GDCD, characterising their duties and delegating a director to every division.

\section{Executive committee}

The committee is appointed by the Board as per GDCD rules. The president of the committee ensures tasks are executed in an opportune and efficient way and that the workload is equally distributed among individuals (Alamri, 2010). The committee is responsible for:

1. Instituting approaches built up by the GDCD Board and following up on current tasks.

2. Proposing new or elective activities and liaising with Ministries and other legislative bodies for collaboration.

3. Sanctioning security measures when a crisis occurs (once pronounced by the Board).

4. Giving sustenance, garments, safe house and medical aid for those in need in times of crises.

5. Speaking to Saudi Arabia in national and global meetings and courses.

6. Giving the Board a proposed spending plan on a yearly premise.

\section{Volunteers with GDCD}

Volunteers make up the rest of the GDCD and are encouraged to work with the GDCD and to assist with emergencies and disasters (Alamri, 2010).

\section{PROJECT AIMS AND OBJECTIVES}

The aim of this paper is to explore the current status and priorities of disaster management in the KSA. The paper reviews the current literature to identify what is currently known about the effectiveness of disaster management arrangements, policies and plans in the KSA. The following are specific objects of the paper:

- To identify the risk profile and strategies underway to mitigate disaster risk.

- To identify the current status of policy, legislation and organisational arrangements in the KSA. 
Table 3. Publications on natural disasters in the KSA since 2000

\begin{tabular}{|c|c|c|}
\hline Authors & Title & Exclusive Summary \\
\hline $\begin{array}{l}\text { Alshehri et al. } \\
\text { (2016) }\end{array}$ & $\begin{array}{l}\text { Emergency nurses' preparedness } \\
\text { for disasters. Descriptive study }\end{array}$ & $\begin{array}{l}\text { Doctors, nurses and other healthcare providers should have an advanced level of disaster } \\
\text { preparedness due to their important role in responding to disaster victims. However, } \\
\text { studies showed that nurses in SA, presented poor knowledge and confidence during } \\
\text { disasters response. }\end{array}$ \\
\hline $\begin{array}{l}\text { Shuiaa and } \\
\text { Alhamid (2015) }\end{array}$ & $\begin{array}{l}\text { Health Response to Hajj mass } \\
\text { gathering. Journal review }\end{array}$ & $\begin{array}{l}\text { Improved preventive plans for infectious diseases during the hajj include airport } \\
\text { screening, updated vaccination, food and water hygiene, general sanitation and hygiene } \\
\text { education about the use of sterilised shaving razors. }\end{array}$ \\
\hline $\begin{array}{l}\text { Abosuliman et } \\
\text { al. (2014) }\end{array}$ & $\begin{array}{l}\text { Floods Planning and management } \\
\text { in Jeddah. Quantitative/ meta- } \\
\text { analysis study }\end{array}$ & $\begin{array}{l}\text { Lack of community-based resources, inadequate training and coordination of response } \\
\text { organisations and community preparedness were the main elements that the current SA } \\
\text { Disaster Management authorities should take into consideration to implement effective } \\
\text { disaster policies. }\end{array}$ \\
\hline Alamri (2014) & $\begin{array}{l}\text { Emergency Management in Saud } \\
\text { Arabia. Comprehensive Literature } \\
\text { review }\end{array}$ & $\begin{array}{l}\text { Emergency management has substantially improved in terms of responding to major } \\
\text { emergencies in urban and regional areas. This improvement serves the Hajj more } \\
\text { effectively than other regions, i.e., emergencies in crowd have to be managed in timely } \\
\text { manner, thus, the authorities have provided flying paramedics to move faster and save } \\
\text { more time in critical situations. }\end{array}$ \\
\hline Almoaid (2014) & $\begin{array}{l}\text { Hajj Crowd Management. } \\
\text { Qualitative study }\end{array}$ & $\begin{array}{l}\text { Disasters in Hajj are due to poor planning, communication and inadequate directional } \\
\text { information. Pilgrims crushes and stampedes are often caused by poor movement } \\
\text { control and less guidance during the course of rituals. }\end{array}$ \\
\hline Alqahtani (2014) & $\begin{array}{l}\text { Disaster Risks and Preparedness. } \\
\text { Comprehensive Literature Review }\end{array}$ & $\begin{array}{l}\text { In Saudi Arabia, developing industries have disastrous effects on humans and } \\
\text { environment. It threatens the public health by polluting the air to major expulsions and } \\
\text { fires. The authorities have enforced these companies to minimise the effects of any } \\
\text { activities, however, poor and uneducated residents found to be most affected by these } \\
\text { activities due to the inadequate public awareness. }\end{array}$ \\
\hline $\begin{array}{l}\text { Abubakar et al. } \\
\text { (2012) }\end{array}$ & $\begin{array}{l}\text { Global prevention of infectious } \\
\text { diseases in Mass gatherings. } \\
\text { Journal article }\end{array}$ & $\begin{array}{l}\text { Poor sanitation and hygiene are serious cause of spreading infectious disease in mass } \\
\text { gatherings. This is found to be significant from the public health prescriptive among } \\
\text { other respiratory infectious diseases. }\end{array}$ \\
\hline Youssef (2012) & $\begin{array}{l}\text { Investigation for geological } \\
\text { hazards assessments in Jazan. } \\
\text { Conventional approach: Social } \\
\text { survey }\end{array}$ & $\begin{array}{l}\text { Result of the analyses process indicated that there are various of risks of landslides in } \\
\text { the southern region area that due to natural factors such as salt dome, losses soil, sand } \\
\text { dune/drift. This therefore has a major impact on the residents, properties and the } \\
\text { environment as well as on the development projects. }\end{array}$ \\
\hline $\begin{array}{l}\text { Memish et al. } \\
(2009)\end{array}$ & $\begin{array}{l}\text { Establishment of public health } \\
\text { security in Saudi Arabia. Peer } \\
\text { reviewed journal }\end{array}$ & $\begin{array}{l}\text { Comprehensive public health security to control infectious diseases and other epidemics } \\
\text { right in the county borders, by implementing effective screening and monitoring } \\
\text { systems to prevent infectious diseases from arriving into the hajj seasons. }\end{array}$ \\
\hline
\end{tabular}

- To contrast the outlined arrangements with those from other international bodies and thus evaluate the status of preparedness.

- To identify improvement strategies and the impact of modern technology on disaster management.

\section{METHODS}

This paper is a descriptive literature review in which relevant Saudi journals press, medical literature, books, Saudi governmental and organisational websites were used to gather relevant data. The review was conducted based on the recommended Preferred Reporting Items for Systematic Reviews (PRISMA) (Moher et al., 2010). Data was found via the QUT library Database while other databases and resources were also searched including, PubMed, Google Scholar, Science direct and Governmental and Organisational websites/databases.

Databases were searched over the last 10 years using keywords: "Disaster management in Saudi Arabia", "Disaster risks in Saudi Arabia", "floods risks in Saudi Arabia” and "Hajj risks management". Only English articles were included. Identified articles were screened by the principal author through a tiered approach involving screening of titles and abstracts for relevance. Full text articles were then screened for relevance, significance and impact pertaining to disaster management in the KSA. Articles were cross-examined with findings from governmental and organisational websites to ensure accuracy and impact. The most valid information was used in terms of information analysis resulted in accurate recommendations. The selected studies vary from qualitative, quantitative, meta-analysis and mixed studies. The findings and discussion were constructed around the dominant themes identified in the literature.

The search identified ten key articles that appeared to contribute significantly to the evaluation of disaster preparedness (Table 3).

\section{FINDINGS}

One of the main barriers to effective disaster response is the lack of public access to the statistics and the reports on a disaster or event. Accessible information for public awareness is necessary for proper disaster assessment and evaluation. However, the focus of this paper is to identify and review the disaster management, rather than discussing the current prevention approaches and government policy changes.

\section{Floods}

The Jeddah flood in 2009 was a wake-up call for all KSA authorities and agencies, to critically re-evaluate the disaster 
response management plans and policies. This resulted in five areas for improvement and development including training of response teams, identification and coordination of the organisational responsibilities, community awareness and preparedness. Moreover, disaster response and crisis mitigation are considered to be key foundations of disaster management, for both natural and human-related disasters (Abosuliman et al., 2014). Failure to manage the risk and mitigate the impacts, are the main reasons behind catastrophes and destruction (Alamri, 2011). Policies and procedures around risk mitigation and prevention help inform decisions and actions for when a disaster occurs while research-based risk charts of disaster management are developed to identify the high-risk areas for better protection planning and response.

However, several disasters management studies have failed to address the importance of public awareness and education for risk reduction as part of the disaster management strategy. A survey conducted on the students of Prince Sultan Medical College indicated there is a lack of sufficient knowledge regarding disaster response with students reporting 'weak' to 'moderate' knowledge of disaster management and 'poor' knowledge for disaster preparedness (Alrazeeni, 2015).

Rahm and Reddick (2011) emphasised the importance of public awareness, claiming that the most effective plan to prevent disaster risks is to involve communities into disaster management awareness and education (Rahm and Reddick, 2011). They add, poor coordination and communication can delay the effectiveness of implementing disaster management plans particularly from the higher authorities to the local and regional authorities. Hence, communication is an essential component in implementing policies and plans when it comes to disaster management (Rahm and Reddick, 2011).

The KSA is one of the Arab countries that has agreed to adopt the Sendai Framework for Disaster Risk Reduction (DRR) (Saro, 2017). This framework encourages a cohesive risk management approach to disaster preparedness by encouraging a national and community resilience to disasters. It also includes a response and prevention approach in which multiple factors are taken into consideration to reduce the possibility of disaster-related risks (Aitsi-Selmi et al., 2015). Furthermore, this framework envisions the reduction of lifethreatening diseases and improvement of health in the form of a battle against travel-related infections. This is significantly applicable in the context of Hajj where the travellers could be carrying an infectious disease that can be harmful to others (Aitsi-Selmi et al., 2015).

First and foremost, the framework acknowledges that the known risk needs addressed appropriately in order to prevent it or control it from creating a disaster (Aitsi-Selmi et al., 2015). Additionally, the framework states that countries must resolve a risk or disaster issue by strengthening their multisectorial policies, allowing the problem to be addressed at the earliest point. For instance, this framework, and it focuses on enhancing the resilience of the national health care services and collaborative efforts between all health areas to mitigate health and disease risk. This collaborative effort translates to better health and infection control at mass gatherings, such as Hajj, as people are travelling worldwide to attend and may introduce new health concerns during this event.
Vulnerability is evaluated by a country's plan to respond to potential disasters and their economic status (i.e., growth domestic product). The KSA has certain vulnerabilities that can hinder the nation's capacity to face and manage such disasters. For example. The KSA faces vulnerabilities in health and funding that correlate to disaster management response during Hajj and Ramadan while large crowds which limits the time for appropriate disasters preparedness plans.

Generally, arrangements of holidays begin just a month prior to Ramadan. As Ramadan ends there is an influx of people arriving for Hajj in Makkah. This takes up the short period towards the real Hajj season. As there is there is short transition time between Ramadan and Hajj, organisers only have two to four weeks to clean the Holy Mosque and planning the maintenance of the asset. This short transition period makes it difficult for organizers and public safety official to address potential hazards or disaster for these events while having specific procedures in place in case of a disaster. Hence, it is crucial that the KSA government and event organisers have an appropriate time to draft a disaster response management plan. However, it is difficult to implement a proper disaster management when financial and non-financial sectors focus on increasing the capacity of an event and profit rather than improving resources for disaster management (Maben et al., 2010).

A nation's level of readiness in a time of crisis is dictated by the degree of harm and impact on the population and area. Disaster readiness has a direct relationship with a society's level of education as a lack of education brings unawareness and absence which can adversely influence a person's readiness and response to a crisis. It therefore requires the government's support to pave the way for society's awareness through strategic approaches (Muttarak and Pothisiri, 2013).

Another aspect of the disaster management in Saudi Arabia is the religious side of it. Most people who deal with the Muslim community and especially Saudi Arabians, have heard the famous phrase of "If Allah wills for it to happen, it will happen". The government has the important task of educating society that preparing for a disaster is not questioning their faith or values. Islamic lessons express that each individual needs to do their best in playing it safe and having confidence in God and depending on Him. Ignoring the necessity of planning and leaving everything to faith is not considered religiously correct. However, explaining the full aspect of this matter is beyond the scope of this paper.

Studies conducted by the Ministry of Economy and Planning in the KSA noted the emergency disaster alerts are not being received or acknowledged by the community and citizens (Alamri, 2010; The Ninth Development Plan (20102014)). This issue directly correlates with the lack of education on disaster management with society disregarding imperative alerts and thinking faith will always prevail over a disaster or catastrophe. Moreover, 53.1\% of the workforce in Saudi Arabia are foreigners who may not receive public alert messages due to the language barrier and often work in hazardous work areas that may put them in even more risk of a disasters (e.g., construction and operation facilities) (The Ninth Development Plan (2010-2014)). Facilitating the alerting system to carry the message in other languages can significantly contribute to the society awareness. 
All effective prevention methods are required to minimise the risks which may arise in the process of gatherings) (World Health Organization, 2013). Prevention methods and strategies for disasters aim to resolve issues and avoid further harm and preventing lives lost. Qanta Ahmed et al. 2006, argued that, " "We suspect Hajj legacy is an influential factor in regional healthcare but is, as yet, an unquantified entity, presenting an important area for further inquiry. We believe Hajj has been a dual driver for the intense development of healthcare in the Kingdom of Saudi Arabia and the arrival of multinational public health medicine to the region" (World Health Organization, 2015).

\section{Hajj}

One of the major risks contributing to disasters is public gatherings in the form of religious events, like Hajj. The three major areas include: risk assessment, surveillance and the response to a risk. These three areas analyse an entire situation and potential risk while allowing alternative measures to be taken and preventing potential disaster (World Health Organization, 2015). Although Hajj can increase the risk of disaster in the KSA, the country has greatly benefited from hosting this religious event over the years and has led to a great public health improvement. For instance, the country has benefited from the implementation of an improved and diverse healthcare system leading to better health outcomes for its citizens (World Health Organization, 2015).

On the other hand, large global gatherings also create the potential for complex health issues and problems. Focusing efforts on proactive strategies like medical school training, emergency planning and public health awareness campaigns can drastically reduce risk and potential disasters (Bajow et al., 2015). Thus, continuous training, planning, and ongoing evaluation of current plans and policies are key to achieving optimal preparedness for crisis prevention and management.

There is evidence that disaster preparedness arrangements in the KSA have been upgraded in recent years. This has been particularly apparent with Hajj which is not only the most prominent event in the country but also the most highly publicised. However, in recent years there have been concerns regarding the prevention and management of infectious diseases by the governing authorities. For example, residents from regional areas (and other countries) can go to perform the Haji without taking the essential vaccinations or passing through quarantine (Henderson, 2011).

Additionally, evidence concerning the issues of stampedes still requires research although many frameworks have been presented on this matter (Henderson, 2011). There should be a concrete management framework in place to resolve the problem of stampedes, particularly involving pilgrims. Authorities tend to concentrate on a single area or specific problem, like where stampedes occur often, rather than implementing ongoing policies to guide stampede prevention and management overall. An updated framework for the Haji season is necessary with evaluated plans for crowd management (Owaidah, 2015). As stampedes can happen quickly, managing them becomes challenging for personnel involved in risk and disaster management. While the certain measurements and monitoring along with the frameworks can assist in awareness and prevention, all the reasons behind the occurrence of stampedes are still unknown and require further research. Further exploration of the causative factors should involve interacting with the pilgrims who suffered from the stampede and survived. This had been one of the major gaps found in the literature.

Moreover, Hajj is a model event for a stampede to occur with large crowds in condensed areas unless vulnerable areas that are a risk of a stampede are identified and the causes of the incidents are eliminated. For example, lines on the floor at Hajj are marked for optimised spacing between pilgrims while multiple entrances (four levels) and tunnels allowing better flow of people and instigating crowd control. Additionally, one way traveling around Kabba prevents stampedes and pilgrim tents have been replaced with fire resistant fabrics while there has been a restriction regarding the use of open flames to prevent fires.

The issue of climatic conditions in Makkah had also been identified as a significant issue faced during the Hajj. Many approaches to deal with extreme conditions are planned by event coordinators including providing umbrellas and covering sun exposed or open areas that may cause dehydration among pilgrims. Some of these approaches require significant infrastructure investments from the government with many ideas under consideration to ensure safe areas for pilgrims at Hajj (Arab News, 2016).

Recently, activities or routines have changed during the Hajj pilgrimage. Traditionally Haji rituals are followed by activities such as rushing around Kabba, or trying to reach the black stone etc. In recent years, the KSA organisation for Haji have been educating pilgrims about the harm associated with some of these activities, particularly if pilgrims are at a greater risk of harm (e.g., frailer, children, immunocompromised etc.).

New innovations have been implemented to facilitate prevention and risk management during Hajj and other religious events in the country. For instance, sensor devices have been installed around the Kabba to identify and control crowd gathering. The sensor devices use radio frequency identification tags (RFID) that help identify overcrowding, congestion and risk of stampedes (Yamin et al., 2008). The RFID tags are small devices known as 'VerChips', containing an individual's information such as personal contacts, address, current location and medical history for better response management in case of any issues (Yamin et al., 2008). The sensor device and RFID tags work together with an integrated database system, which is effective in monitoring and controlling the movement of pilgrims during the Hajj season (Yamin et al., 2008).

In recent years, there has been significant collaborations between the WHO and the Saudi Arabia Ministry of Health, concerning the surveillance and control of infectious diseases at Hajj. As a result, the ministry has been establishing plans and policies, internationally and domestically, to protect the health of pilgrims and citizens during and after Hajj seasons. For instance, new control measures and preventive policies such as screening and mandatory vaccinations of tuberculosis, yellow fever and meningitis and other epidemic illnesses have been implemented mitigate health risks caused by mass gathering related illnesses (Memish et al., 2009). Additionally, general medical tests have been implemented to ensure 
optimal sanitary and health conditions for all pilgrims at the event. For example, pilgrims are asked to take medications (a course of Ciprofloxacin, and Loperamide) for three days prior to Hajj to reduce bacterial infection like respiratory tract infections. General health and hygiene education like the importance of staying hydrated and the use of face-masks at mass gatherings are also provided in advance. After the pilgrimage, general health check-ups are conducted on pilgrims for early recognition of symptoms of possible illnesses. Hence, health care services during the Hajj season provide preventive care to all pilgrims such as hygiene and health education programmes, vaccines and chemoprophylaxis for influenzas at quarantine services, airports and harbours (Almalki et al., 2011).

Furthermore, emergency services and paramedics are on high alert and strategically located during the Hajj season while new emergency departments and hospitals have been built within the vicinity of the pilgrimage. For instance, in 2009, seven new seasonal hospitals with 3,408 non-emergency beds and 176 emergency beds were built in Makkah. Above and beyond these, the KSA government has introduced disaster management programs to healthcare providers in order to respond to disaster victims effectively. Disaster plans, training drills and roles description were provided to hospitals staff (Almalki et al., 2011).

\section{Road Traffic Accidents}

Over the last 20 years the KSA has made significant improvements in using the accident reporting system to record the number of road traffic accidents taking place each year and the common causes of these incidents. In recent years, new laws have been implemented to improve public safety on the roads by adding speed cameras and mandatory seat belts for all passengers in vehicles. The WHO has introduced five main categories of road safety; road safety management or policy, road infrastructure, safe vehicles, road users' safe behaviour, and post-crash care (World Health Organization, 2013). A recent study (Mansuri et al., 2015) identified and summarized the main causes of road traffic accidents in the various regions of the KSA. The authors of the study (Mansuri et al., 2015) noted that the main causes of accidents in both urban to rural areas were to due poor road safety, road infrastructure and highspeed driving particularly in the capital cities. The Department of Road Safety and Road Traffic Accidents has introduced a new technology called 'Saher' to improve road safety and reduce car accidents (meaning attentive). This technology is an integrated system that provides traffic management, vehicle location, plate number recognition, sign recognition, CCTV and automatic law enforcement system (Alghnam et al., 2017). The system provides a network of control by utilising advanced highspeed cameras (Alghnam et al., 2017).

\section{DISCUSSION}

The KSA's investment in disaster management and response is significantly higher than its neighbouring countries. One reason is the size of the country and annually hosting the Hajj pilgrimage and economy of the country compared to its neighbouring countries. Although the KSA has made tremendous progress over the last few years to improve risk management and disaster prevention plans, potential risks and disasters are still inevitable. In recent years, the focus to reduce the road traffic accidents has increased not only in the KSA but also worldwide. For instance, the Saher technology is significantly reducing the number of fatalities and injuries on Saudi Arabian roads. However, the Safer system is not yet fully utilised in the country as the system only applies to drivers and not motorcyclists while inadequate signage for road speeds are an ongoing issue for drivers.

Since 2016, the population of Muslims is growing at the rate of $1.7 \%$ compared to the population growth of $1.1 \%$ per year (Grim and Hsu, 2011; United Nation, Department of Economic and Social Affairs Population (UN DESA)). Management of large religious gatherings such as Ramadan visits and Hajj, have been the under improvement for the past ten years to keep up with increasing numbers at these events. These improvements include construction of Makkah metro and allocating helicopter rescue teams specifically at Hajj. Infrastructure developments and changes to current buildings are also being implemented to support future developments. However, building helipads around the holy mosque as well as further investment in public transport facilities are slow processes and costly. Additionally, visiting Makkah or Kaaba is not limited to just Hajj, as Muslims can visit Kabba at any time of the year for other religious events. Therefore, ongoing infrastructure improvements are necessary for the city of Makkah due to ongoing events in the city but can also be difficult to achieve. Moreover, many infrastructure projects have ambitious completion dates, sometimes in a few months only making it difficult to complete before the next religious event and influx of pilgrims. For example, building tunnels for metro systems requires road closures in Kabbah has been difficult to complete with the ongoing religious events in the city.

Furthermore, the lack of local expertise and necessary knowledge in the country is another barrier to agile development of disaster management planning and is heavily dependent on foreign experts and labours which is costing approximately US $\$ 60$ billion per year. As many may agree, the roots of these barriers are in education system of the country and the culture of the society. There is a perception in the country that some careers avenues are not important and not worth developing, including the hospitality industry, trades (e.g., construction, carpentry or plumbing etc.) or some medical careers (e.g., nursing). Thus, the country is heavily relies on foreign skilled workers and pay a premium for their expertise (Maben et al., 2010).

When a nation is not involved in the basic needs of the society, knowledge advancement cannot be achieved, and the country cannot advance their economy and industries. This requires training, education and social awareness to change the trend. In terms of disaster management, the KSA has not been collaborating and participating with the outside world for innovative solutions to prepare better for disaster risk and the overall response the country has for disasters. Therefore, these factors need to be addressed to improve research regarding emergency and disaster management. 
The religious beliefs need to be at the forefront of discussions for disaster management planning and preparedness. According to a national survey conducted by Alshehri, Rezgui \& Nat (2013), the majority of Saudi Arabians show strong faith and hold a perception that "disasters are punishment from God” (Alshehri et al., 2016). This perception can have negative impacts on disaster response and intervention. Therefore, community involvement in disaster risk management should be encouraged by education, training, volunteering work and providing effective public access to emergency and disaster information and resources.

Finally, disaster management has been lacking within healthcare facilities since disasters can have on detrimental effects on public health resources. A study done by Alshehri (2017) asked 72 participants from two major hospitals in the capital city (Riyadh) whether there were any disaster management policies implemented in their hospital (Alshehri, 2017). Participants stated that hospitals have disaster plans or policies in place but a majority of staff do not understand their roles in disasters response. Moreover, participants who are inexperienced in dealing with disasters showed less confidence in their skills than those who have responded to disasters before (Alshehri, 2017). This remark may be due to the poor attendance rate by hospital staff to the disaster management sessions, and insufficient implementation of disaster management policies. The Ministry of Health has introduced disaster management programmes to better educate healthcare providers in responding to disaster victims.

\section{LIMITATIONS}

This systematic review was limited by the data available from previous studies and reports. Anyone who has been conducting research on the KSA agrees that publicly available data is limited as the government is not transparent with its policies and strategies and whether these policies have been implemented or are effectively working. The reporting quality is another limitation where most data could be reported in newspapers and limited organisational websites the government is not releasing full reports on some events for homeland security purposes.

\section{RECOMMENDATIONS AND CONCLUSION}

This paper and current research has revealed some insight into the current risks and vulnerabilities facing the KSA. A list of the country's top disasters has been analysed in this paper and recommendations have been provided and current disaster management policies, plans and prevention strategies have been stated. The country's disaster management system is unique as it encompasses events such as Hajj, one of the largest annual mass gathering events in the world. This annual event should encourage disaster management committees, research institutions and other organisations to use Saudi Arabia's disaster management program as a model and learn from its successes and failures. Thus, this paper aims to serve as an example for reporting current policies and a reference for future research on disaster and risk management in the KSA.

\section{REFERENCES}

Abosuliman, S. S., Kumar, A. and Alam, F. (2013). Disaster preparedness and management in Saudi Arabia: an empirical investigation. International Journal of Social, Human Science and Engineering, 7(12), 295-299.

Abosuliman, S. S., Kumar, A. and Alam, F. (2014). Flood disaster planning and management in Jeddah, Saudi Arabia-a survey. Paper presented at: Fourth International Conference on Industrial Engineering and Operations Management, Bali, Indonesia, 7-9 January 2014.

Abubakar, I., Gautret, P., Brunette, G. W., et al. (2012). Global perspectives for prevention of infectious diseases associated with mass gatherings. The Lancet infectious diseases, 12(1), 66-74. https://doi.org/10.1016/S14733099(11)70246-8

Aitsi-Selmi, A., Egawa, S., Sasaki, H., Wannous, C. and Murray, V. (2015). The Sendai framework for disaster risk reduction: Renewing the global commitment to people's resilience, health, and well-being. International Journal of Disaster Risk Science, 6(2), 164-176. https://doi.org/ 10.1007/s13753-015-0050-9

Alamri, Y. A. (2010). Emergency management in Saudi Arabia: Past, present and future. Un Of Christchurch report, New Zealand, 21.

Alamri, Y. A. (2011). Rains and floods in Saudi Arabia. Crying of the sky or of the people? Saudi medical journal, 32(3), 311-313.

Alghnam, S., Alkelya, M., Alfraidy, M., Al-Bedah, K., Albabtain, I. T. and Alshenqeety, O. (2017). Outcomes of road traffic injuries before and after the implementation of a camera ticketing system: a retrospective study from a large trauma center in Saudi Arabia. Ann Saudi Med. 37(1), 1-9. https://doi.org/10.5144/0256-4947.2017.1

Almalki, M., FitzGerald, G. and Clark, M. (2011). Health care system in Saudi Arabia: an overview. East Mediterr Health J. 17(10), 784-793. https://doi.org/10.26719/2011.17.10.784

Alqahtani, S., Alraddadi., S., Almourey., R., Alradadi., R., Alradadi., R. and Shehri, W. (2017). Knowledge and practice in chronic pain management among primary healthcare physicians. International Journal of Advanced Research, 5(1), 1954-1964. https://doi.org/10.21474/ IJAR01/2965

Alrazeeni, D. (2015). Saudi EMS Students' Perception of and Attitudes toward Their Preparedness for Disaster Management. Journal of education and practice, 6(35), 110116.

Al-Shareef, A. S., Alsulimani, L. K., Bojan, H. M., et al. (2017). Evaluation of Hospitals' Disaster Preparedness Plans in the Holy City of Makkah (Mecca): A Cross-Sectional Observation Study. Prehospital and disaster medicine, 32(1), 33-45. https://doi.org/10.1017/S1049023X16001229

Alshehri, B. (2017). Emergency nurses' preparedness for disaster in the Kingdom of Saudi Arabia. Journal of Nursing Education and Practice, 7(3), 6. https://doi.org/ 10.5430/jnep.v7n3p101 
Alshehri, S. A., Rezgui, Y. and Li, H. (2016). Public perceptions and attitudes to biological risks: Saudi Arabia and regional perspectives. Disasters, 40(4), 799-815. https://doi.org/ 10.1111/disa.12179

Alzahrani, A. G., Choudhry, A. J., Al Mazroa, M. A., Turkistani, A. H., Nouman, G. S. and Memish, Z. A. (2012). Pattern of diseases among visitors to Mina health centers during the Hajj season, 1429 H (2008 G). Journal of infection and public health, 5(1), 22-34. https://doi.org/10.1016/j.jiph.2011.10. 003

Bajow, N., Djalali, A., Ingrassia, P. L., Ageely, H., Bani, I. and Della Corte, F. (2015). Disaster medicine curricula in Saudi Arabian medical schools. Journal of Emergency Medicine, Trauma and Acute Care, 2015, 8. https://doi.org/10.5339/ jemtac. 2015.8

Bronfman, N. C., Cisternas, P. C., Repetto, P. B. and Castañeda, J. V. (2019). Natural disaster preparedness in a multihazard environment: Characterizing the sociodemographic profile of those better (worse) prepared. PloS one, 14(4), e0214249. https://doi.org/10.1371/journal.pone.0214249

Centre for Research and Epidemiology Disasters (CRED) (2017). Natural Disasters 2017. Brussels: CRED; 2018 EMDAT file dated 02/07/2018. Available at: https://cred.be/sites/default/files/adsr_2017.pdf

Coppola, D. P. (2006). Introduction to international disaster management. Elsevier.

Coppola, D. P. (2007). Introduction to international disaster management. Elsevier.

Grim, B. J. and Hsu, B. (2011). Estimating the global Muslim population: Size and distribution of the world's Muslim population. Interdisciplinary Journal of Research on Religion, $7,2$.

Henderson, J. C. (2011). Religious tourism and its management: The hajj in Saudi Arabia. International Journal of Tourism Research, 13(6), 541-552. https://doi.org/10.1002/jtr.825

International Disaster Database (EM-DAT). Center for Research on the Epidemiology of Disasters (CRED). Country Profile: natural disasters (2010). Available at: http://www.emdat.be/country-profile

Khammash, M. R. and Al-Shouha, T. F. (2006). Do road traffic accidents increase during the fasting month of Ramadan. Neurosciences (Riyadh, Saudi Arabia), 11(1), 21-23.

Lindell, M. K., Perry, R. W., Prater, C. and Nicholson, W. C. (2006). Fundamentals of emergency management. Washington, DC, USA: FEMA.

Maben, J., Al-Thowini, K., West, E. and Rafferty, A.-M. (2010). Uneven development: comparing the indigenous health care workforce in Saudi Arabia, Bahrain and Oman. International journal of nursing studies, 47(3), 392. https://doi.org/10.1016/j.ijnurstu.2009.07.008

Mansuri, F. A., Al-Zalabani, A. H., Zalat, M. M. and Qabshawi, R. I. (2015). Road safety and road traffic accidents in Saudi Arabia: a systematic review of existing evidence. Saudi medical journal, 36(4), 418. https://doi.org/10.15537/ smj.2015.4.10003
Memish, Z., McNabb, S., Mahoney, F., et al. (2009). Establishment of public health security in Saudi Arabia for the 2009 Hajj in response to pandemic influenza A H1N1. The Lancet, 374(9703), 1786-1791. https://doi.org/10.1016/ S0140-6736(09)61927-9

Moher, D., Liberati, A., Tetzlaff, J. and Altman, D. G. (2010). Preferred reporting items for systematic reviews and metaanalyses: the PRISMA statement. International journal of surgery (London, England), 8(5), 336-341. https://doi.org/10.1016/j.ijsu.2010.02.007

Muttarak, R. and Pothisiri, W. (2013). The role of education on disaster preparedness: case study of 2012 Indian Ocean earthquakes on Thailand's Andaman Coast. Ecology \& Society, 18(4), 1-16. https://doi.org/10.5751/ES-06101180451

OEC (2017). Saudi Arabia (SAU) Exports, Imports, and Trade Partners.

Owaidah, A. A. (2015). Hajj crowd management via a mobile augmented reality application: a case of The Hajj event, Saudi Arabia (Masters Thesis), University of Glasgow.

Rahm, D. and Reddick, C.G. (2011). US city managers' perceptions of disaster risks: Consequences for urban emergency management. Journal of Contingencies and Crisis Management, 19(3), 136-146. https://doi.org/10.1111/ j.1468-5973.2011.00647.x

Saro, R. (2017). Arab region sets stance for Global Platform for Disaster Risk Reduction. Available at: https://www.unisdr. org/archive/52956 (Accessed: January 9, 2020).

Saudi Gazette (2016, 1 January) Saudi Arabia records 526,000 road accidents annually report. Al Arabiya. Available at: http://english.alarabiya.net/en/News/middleeast/2016/01/01/Report-Saudi-Arabia-records-526-000road-accidents-annually.html

Shujaa, A. and Alhamid, S. (2015). Health response to Haji mass gathering from emergency perspective, narrative review. Turkish Journal of Emergency Medicine, 15(4), 172176. https://doi.org/10.1016/j.tjem.2015.02.001

Soomaroo, L. and Murray, V. (2012). Disasters at mass gatherings: lessons from history. PLoS currents, 4, Rrn1301. https://doi.org/10.1371/currents.RRN1301

The Ninth Development Plan (2010-2014). National Economy under the Ninth Development Plan. Ministry of Economy and Planning, Kingdom of Saudi Arabia. Available at https://www.mep.gov.sa/en/AdditionalDocuments/PlansE N/9th/Ninth\%20Development\%20Plan\%20-\%20Chapter \%204\%20-\%20National\%20Economy\%20Under\%20The\% 20Ninth\%20Development\%20Plan\%20.pdf

United Nation, Department of Economic and Social Affairs Population (UN DESA). Population Devision Publication. Available at: https://www.un.org/en/development/desa/ population/publications/index.asp (Accessed: Accessed: July 18, 2020).

United Nation, Office for Outer Space Affairs (UN SPIDER). The UN and Disaster Management. Available at: http://www.un-spider.org/risks-and-disasters/the-unand-disaster-management (Accessed: July 18, 2020). 
World Health Organization. (2009). Annual Disaster Statistical Review.

World Health Organization. (2013). Global Status Report on Road Safety 2013.

World Health Organization. (2015). Public health for mass gatherings: key considerations.
Yamin M, Mohammadian M, Huang X, Sharma D. RFID Technology and Crowded Event Management. IEEE Computer Society; 2008. https://doi.org/10.1109/ CIMCA.2008.233

\section{APPENDIX 1}

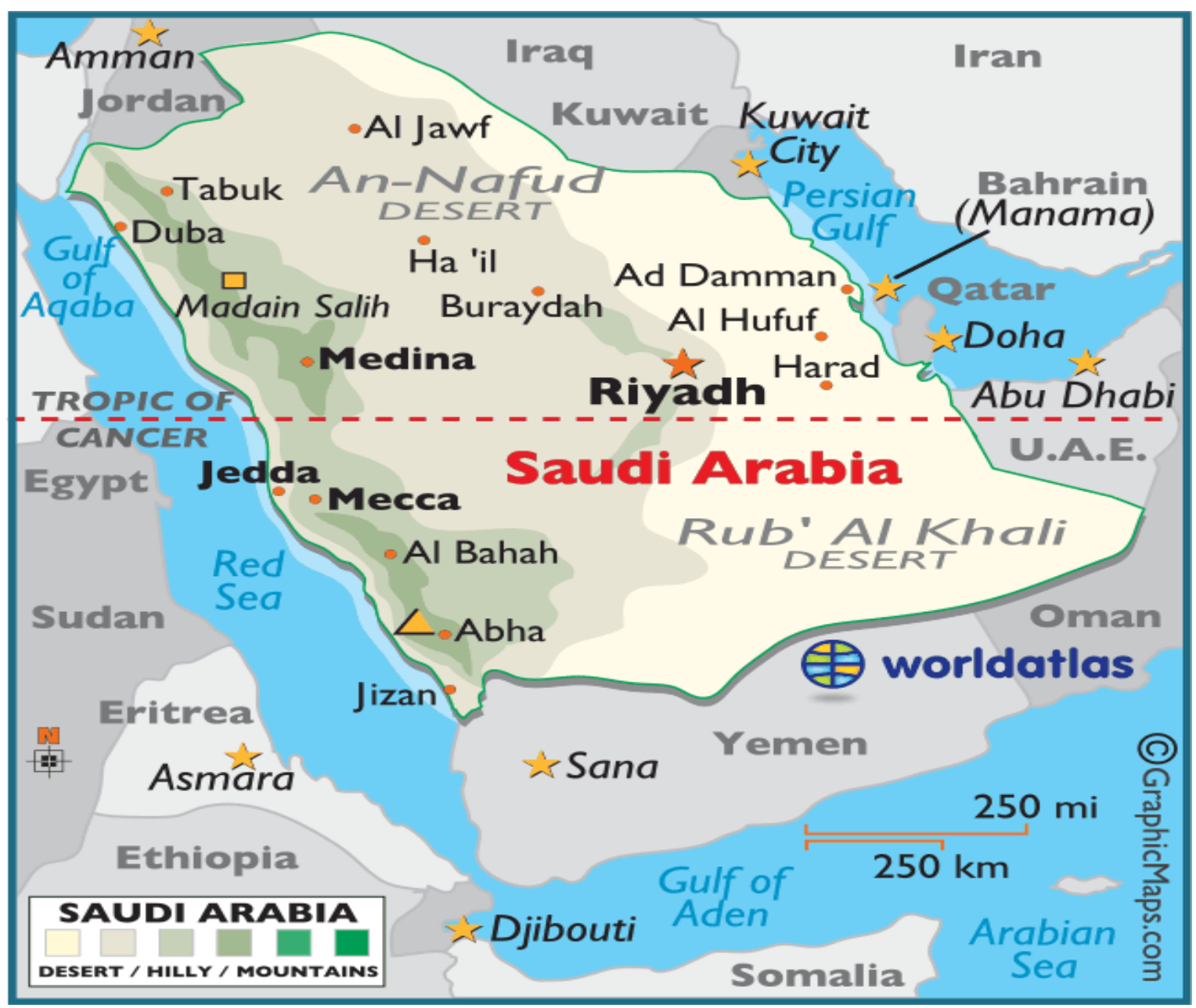

Figure. Map of Saudi Arabia

Source: https://www.worldatlas.com/webimage/countrys/asia/sa.htm 


\section{APPENDIX 2}
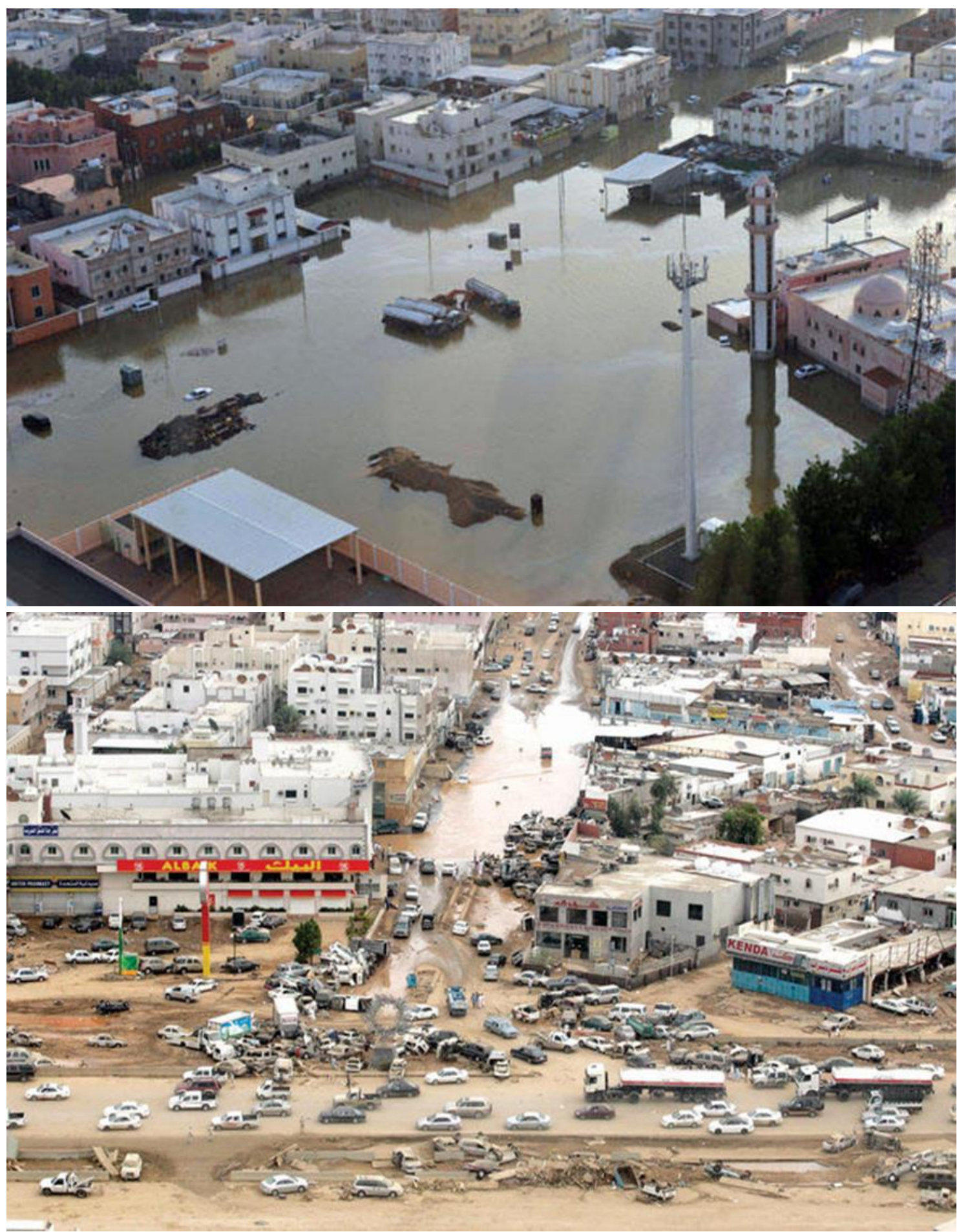

Figure. Views of Jeddah in the aftermath of 2009 floods

Source: http://www.arabnews.com/node/1016971/saudi-arabia 